\title{
Colorimetric Cell Viability Assay
}

National Cancer Institute

\section{Source}

National Cancer Institute. Colorimetric Cell Viability Assay. NCI Thesaurus. Code C95027.

A colorimetric assay that can assess the viability of cells by quantitation of the reduction of a yellow tetrazolium salt substrate to a product that has a purple color. This assay can measure the cytotoxicity of a chemical or drug by determining the affect of treatment on cell viability. 